\title{
Tectonic and Topographic Framework of Political Division ${ }^{1}$
}

\author{
Brandon J. McElroy, ${ }^{2}$ Bruce H. Wilkinson, ${ }^{2}$ \\ and Edward D. Rothman ${ }^{3}$
}

\begin{abstract}
Boundaries between the various topographic, geologic, and socio-political entities that span the Earth's continental surfaces are determined by a myriad of complexly interrelated natural and/or cultural factors. Areas of large river basins, of lithologic units on geologic maps, and of nations exhibit size frequency distributions that are closely approximated by density functions in which diameters of individual areas are distributed exponentially. As such, size distributions of each type of surface unit are closely modeled as randomly delimited areas. In other words, if one were to walk in a straight line across any particular continent, each step along that transect would embody some random continuous probability of passing out of a major drainage basin, or out of an area of more or less homogeneous rock type, or from one country to another. Moreover, this simple truism gives rise to area frequency distributions for large river basin or outcrop or nation area that are primarily dependent on the number of basins or outcrops or countries that exist across that particular landmass. As a consequence, the size frequencies of these areal units can be closely predicted knowing only the total area under consideration and the number of drainage basins, outcrop areas, or nations that exist within the area. The similarity between area frequencies of large river basins and rock types and nations suggests a nontrivial component of geologic influence on the partitioning of continental surfaces into major political divisions, and implies that cultural and economic factors, which serve to divide and unite political entities, do so within a geological framework.
\end{abstract}

KEY WORDS: country sizes, tectonics, area exceedence, geologic maps.

\section{INTRODUCTION}

In the general process of describing the lateral extent of various two-dimensional features that compose the Earth's surface, contiguous areas can be delineated by the nature of either interior or boundary properties. For example, nations are distinguished by those governmental bodies that rule within them, whereas river basins are delimited by the interfluves that divide them. A necessary step toward understanding those natural processes that serve to partition heterogeneous

\footnotetext{
${ }^{1}$ Received 2 January 2003; accepted 23 August 2004.

${ }^{2}$ Department of Geological Sciences, University of Michigan, Ann Arbor, MI 48109, U.S.A.; e-mail: eustasy@umich.edu.

${ }^{3}$ Department of Statistics, University of Michigan, Ann Arbor, MI 48109, U.S.A.
} 
regions into smaller domains of generally greater homogeneity is to describe their relative sizes (e.g., Simon, 1978). Over the last three decades, advances in remote sensing technology, including satellite altimetry, global positioning systems, and digital cartography have allowed for these tasks to be accomplished with increased accuracy and efficiency (e.g., Schanda, 1986; Jenson and Dominingue, 1988). From such data, numeric models and functional relations can then be derived to test hypotheses about the origins of size frequency distributions and their ramifications for understanding the character of Earth-surface divisions.

From a perspective of the natural sciences, it has long been recognized that the surface of the planet has been significantly modified by tectonism and, as a first approximation, the recency and intensity of such deformation is manifest both as geological and physiographic complexity along orogenic belts. Because deformation of the Earth's surface is primarily expressed as increased topographic relief and dissection of lithologic units that comprise crustal rocks, it is at least qualitatively apparent that tectonic deformation must also have a direct effect on regional physiography and the lateral distribution of different rock types, and might also significantly predispose geo-political boundaries to coincide with natural barriers of regional topography.

To examine sizes of geologic, physiographic, and governmental entities at Earth's surface, we have therefore tabulated global topographic, lithologic, and geopolitical data from a variety of sources. In the following we briefly describe these data and sources, show cumulative area distributions for each, and derive a physical model that serves to characterize sizes of areas that result from different schemes of Earth-surface division. We then discuss these results in a context of interrelations between tectonic processes and the establishment of geopolitical divisions, and the central role of indeterminate Poisson processes in the segmentation of land surface area into geologic, hydrologic, and political realms.

\section{Sizes of Drainage Basins, Rock Exposures, and Countries}

Areas drained by axial channels and their tributaries serve to apportion landmasses into drainage basins; the vast majority reach some point of coastal discharge. Size attributes of the Earth's major rivers are given by Hovius (1998); these comprise 97 large basins with a mean area of $\sim 618 \times 10^{3} \mathrm{~km}^{2}$, and they cover $59 \times 10^{6} \mathrm{~km}^{2}$ (i.e., $40 \%$ ) of continental area. Exceedence rank for river length, basin length, and basin area define relatively regular patterns of size variation; both measures of length are well modeled by exponential distributions (Fig. 1).

Areas of rock units exposed at continental surfaces were derived from the Generalized Geological Map of the World and Linked Databases (Kirkham and others, 1995). This is a digital data set composed of geographically referenced rock unit polygons and fault lines for each continent, with data on area, age, rock or fault type, and name information for each polygon or line. From embedded 


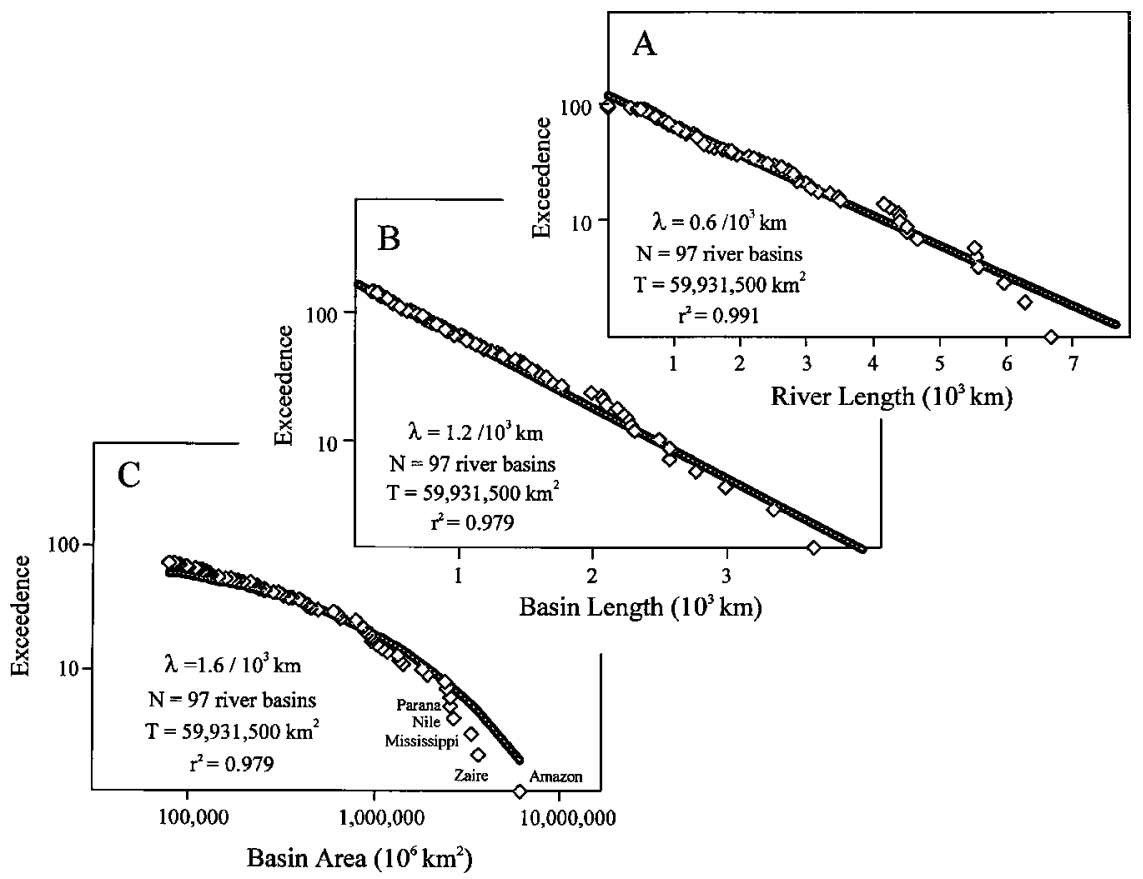

Figure 1. Lengths of the Earth's major rivers (A), and lengths (B) and areas (C) of their drainage basins from data in Hovius (1998) relative to size exceedence (number bigger). These measures of river size are closely approximated by distributions (dashed lines) where $\lambda$, defines the probability of terminating a length segment or that exiting a drainage area per kilometer of transect.

attribute files, area frequency distributions of plutonic, metamorphic, and sedimentary lithologies were determined, and plotted relative to their exceedence rank (Fig. 2). These three lithologies comprise $\sim 78.9 \%$ of exposed continental rock, the balance consisting of glacial ice (10.9\%), volcanic (6.5\%), and unclassified $(4.1 \%)$ complexes. Although mapping at this scale is rather coarse (mean area $=18,321 \mathrm{~km}^{2}$, about the size of New Jersey), relative size (manifest as the number of defined lithosomes) does not alter the shapes of these distributions.

Sizes of countries (defined as United Nations Member States in December of 2000; Central Intelligence Agency, 2000) exhibit the same general type of distribution. These include 189 nation-level political divisions with a mean area of $528,676 \mathrm{~km}^{2}$. When plotted relative to exceedence rank, size frequencies for these nations (Fig. 3) are the same as those exhibited by global river basins (Fig. 1C) and outcrops (Fig. 2).

Lengths of major river courses (Fig. 1A) and surrounding drainage basins (Fig. 1B) exhibit a strong positive correlation, where stream lengths are about twice that of basin lengths $\left(r^{2}=0.82\right)$. More importantly, both measures of size 


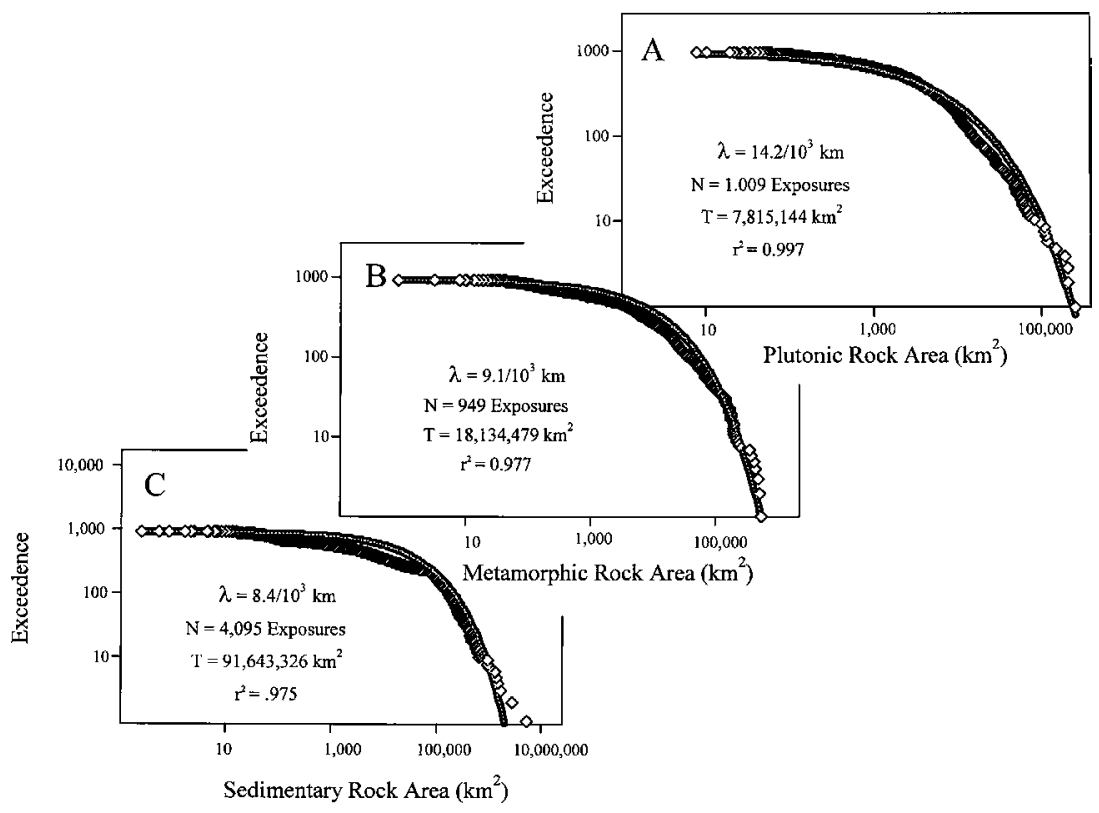

Figure 2. Areas of plutonic (A), metamorphic (B) and sedimentary (C) rock exposures extracted from the global geologic map by Kirkham and others (1995). Like major drainage basins, a model in which land area is randomly segmented into subregions of more or less homogeneous lithology closely approximates riverine area frequency.

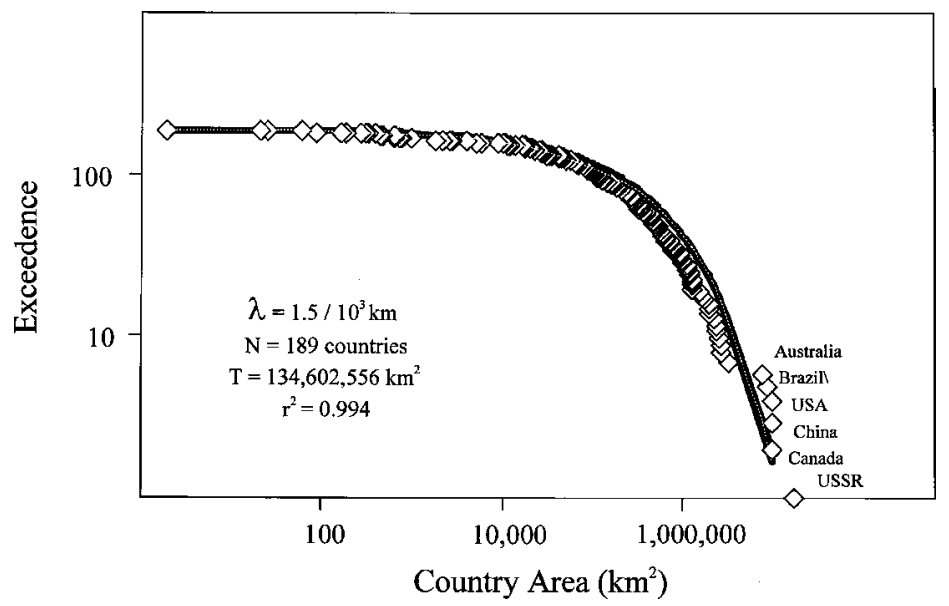

Figure 3. Sizes of 189 U.N. member countries (Central Intelligence Agency, 2000). Country size frequency is closely approximated by a distribution in which $\lambda$, defines the probability of exiting that country per kilometer of transect. 
exhibit exponential decreases of length with linear decreases in exceedence rank (number of larger basins), a pattern that would result if lengths were derived from a population that exhibited a uniformly random probability of segmentation per unit of river or basin length.

In a similar manner, areal extents of drainage basins, of lithologic units, and of U.N. countries exhibit nearly identical size distributions reflecting the fact that locations of region boundaries relative to region centers (region radii) are also exponentially distributed. On the basis of the similarities of these area size frequencies, we suggest that distances across generally homogeneous regions of surface hydrology, geology, and political constitution are, as a first approximation, incidentally distributed across the Earth's continents. Here, we first derive a numerical representation of such first-order control, and then discuss the insights derived from, and limitations inherent in, such a view.

\section{General Model for Earth-Surface Partitioning}

To evaluate the validity of a probabilistic function that describes the size distributions of these (and perhaps other directly and/or indirectly related) areas of various divisions of the Earth's surface (e.g., Meybeck, 1995), we start with a simple physical model. Given a set of areas in which the distance in any direction between any central point and its surrounding boundary, or the distance between any two boundaries, is a continuous random variable, and assuming that boundaries are not correlated with longitude or latitude and that distances between them are similarly uncorrelated, a forward model for the size distribution of areas can be derived where lengths of area diameters are exponentially distributed. Given an exponential probability density function for diameters

$$
f_{\left(D_{i}\right)}=\lambda e^{-\lambda D_{i}}
$$

where $D_{i}$ is the length of the $i$ th diameter and $\lambda$, is the exponential constant determined by a ratio of the number of diameters in the population to the sum of their lengths. Because the relation between area and diameter for generally equidimensional entities such as river basins, outcrops, and countries, is known, the equivalence for the expected values of the $i$ th area and $i$ th diameter can be written as

$$
E\left[A_{i}\right]=E\left[c \times D_{i}^{2}\right]
$$

where $c$ is a constant. In a physical sense, $c$ would be $\pi / 4$ for circular areas, unity for squares, and the ratio of the sides for rectangles. With Equation (2), the 
expected value of the $i$ th area can be calculated in terms of the constant $\lambda$

$$
E\left[A_{i}\right]=\int_{\infty} A_{i\left(D_{i}\right)} f_{\left(D_{i}\right)} d D_{i}
$$

Assuming $c=\pi / 4$, Equation (3) produces

$$
E\left[A_{i}\right]=\pi / 2 \lambda^{2}
$$

By combining Equation (4) with the relation for $T$, the total area, as the sum of the $N$ areas, the expression for $\lambda$, in terms of the population of areas can be written as

$$
\lambda=(\pi N / 2 T)^{0.5}
$$

Given the expression for $\lambda$, in terms of area, the cumulative distribution of diameters can be found by integrating Equation (1) and substituting the relation of the $i$ th area to the $i$ th diameter

$$
F_{\left(D_{i}\right)}=\int_{D} \lambda e^{-\lambda D_{i}} d D_{i}=1-e^{-\lambda f\left(A_{i}\right)}
$$

The final step in deriving the model relation for area and rank within the population is to multiply the exceedence distribution $\left(1-F_{D_{i}}\right)$ by $N$ and simplify for diameter as a function of area

$$
\operatorname{Rank}\left(A_{i}\right)=N \times e^{-\left(p A_{i}\right)^{0.5}}
$$

where rank is the size rank of the $i$ th area within the population and $p=2 N / T$. The result in Equation (7) yields the size distribution of a set of areas from only two pieces of information: the total number of areas in the population, and the total area occupied by that population. These are the dotted solid lines in Figures $1 \mathrm{C}-3$, and are dependent only on $N$ and $T$.

\section{CONCLUSIONS}

Comparison of the theoretical size frequency distribution for units with randomly delimited boundaries (dashed lines in Figures 1C-3) with areal data from large river basins, plutonic, metamorphic, and sedimentary rock outcrops, and with U.N. country sizes yields Pearson correlation coefficients of $0.979,0.997,0.977$, 0.975 , and 0.961 , respectively. We therefore suggest that a theoretical model in which land area is randomly segmented closely approximates sizes of topographic, 
geologic, and political divisions of the Earth's surface. Values of $\lambda$, for river basins, plutonic, metamorphic, and sedimentary rocks, and countries are 1.6,14.2, 9.1, 8.4, and $1.5 / 10^{3} \mathrm{~km}$, respectively. These values represent the probability of crossing some area boundary per linear kilometer of transect length.

Similarity of size frequency distributions among populations of large river basins, regional outcrop areas, and nations not only imply that their boundaries occur more or less at random, but also suggest that the location of tectonic, physiographic, and political units are closely interrelated. Figure 4, for example, shows the distribution of drainage basin, major rock lithosomes, and countries across the South American continent. From these maps, is immediately apparent that the three patterns of partitioning are not unrelated. In addition to the fact that larger drainages and outcrop areas predominate on more stable cratonic crust (Pampas, Amazon and Parana Basins, Guyanan and Brazilian Shields) east of the Andean, Patagonian, and Pampean orogenic belts, many boundaries between nations correspond to drainage divides between adjacent river basins. To the extent that regions arising from geologic histories of tectonic deformation and erosion at least in part correspond to socio-political divisions manifest as national borders, it is also necessary to acknowledge the consequences of cultural and economic factors on country sizes within such a geologic framework of political divisions.

Archaeologists and historians have long recognized that rivers played a central role in the organization of early human civilizations. Sources of water commonly augmented settlement in various regions, such as early Egyptian and Mesopotamian settlements where the Nile, Tigris, and Euphrates Rivers run through the nearly barren desert lands (Starr, 1991). Furthermore, many rivers (e.g., the Zaire, Danube, or Amur) serve as effective political barriers, and multiple rivers bound many nations (e.g., Poland, United States or Paraguay); the border between Peru and Colombia is the Putumayo River (Fig. 4). At a similar scale of consideration, other physiographic features are equally prominent in the delineation of political divisions. Childe (1952) for example, noted that most Near Eastern prehistoric cities and villages were bound on the west by the Sahara Desert and Mediterranean Sea, on the east by the Thar Desert and Himalayan Mountains, on the north by the Balkan, Caucasus, and Hindu-Kush Mountains, and on the south by the Tropic of Cancer. The border between Argentina and Chile, and that between Brazil and Venezuela largely correspond to high interfluves (Fig. 4).

Although those features did not explicitly inhibit dispersion of people and cultures, they most surely retarded travel and communication, and functioned as coarse climatic and thus agricultural boundaries as well. As a modern analog, mountain ranges and deserts divide current population centers and also contain boundaries of many nations (e.g., Norway and Sweden or Mongolia and China, respectively). As another example, coasts almost ubiquitously serve in duality as both natural and political boundaries. Given the obvious relations that must at least qualitatively serve to link Earth's plate tectonic framework to the location 


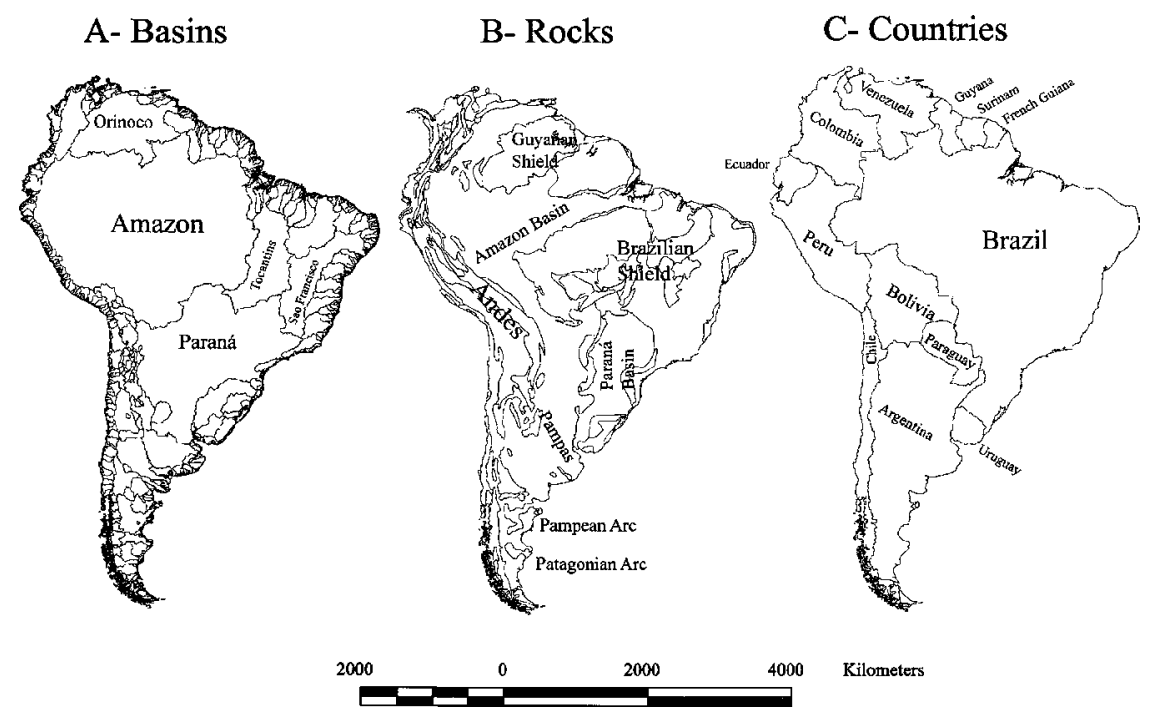

Figure 4. South American drainage basins (A), outcrops (B), and countries (C). Outcrops from attribute files in Kirkham and others (1995). Drainage basins derived from a sinusoidal projection of GTOPO30 DEM data as described by Jenson and Dominingue (1988). Note that while each pattern of division has its own particular attributes, unit sizes, shapes, and boundaries also exhibit a noteworthy, albeit qualitative, association.

of coasts and to the development of surficial drainages, and those that link geomorphic processes and features to the spread of human affects, it is perhaps not surprising that outcrops, river basins, and countries might exhibit similar size frequencies.

As noted above, only two variables, the number of defined entities and the total area under consideration, determine the size rank of any entity within a population. While the amount of continental land area across the surface of the Earth is finite and largely invariant in the modern world, numbers of entities may be largely a matter of definition. When considering river basins, it can be shown that a power-law distributions fit many size frequency relations (e.g., Hack, 1957; Horton, 1945) such as areas of drainages above randomly determined points along stream channels and above stream confluences. Defining a river basin as that area drained by a channel and all of its tributaries, such power-law distributions imply that one could define an infinitely large number of drainages along divides or coasts. However, because Hovius (1998) only summarized size data for 97 of the largest of these, their area frequency (Fig. 1C) more closely reflects the exponential distribution of channel and basin lengths (Fig. 1A and 1B) than any real measure of upstream watershed area. Although areas of major watersheds comprise less than 
half of total continental area, they clearly are of greater importance than smaller systems in augmenting or impeding nationalization.

Outcrop areas, on the other hand, comprise nearly all of exposed land at the Earth's surface. As such, their size frequencies are only dependent on the number regions deemed to be lithologically homogeneous, a designation that almost entirely relates to scale of mapping. Values of $\lambda$, determined from Kirkham, Chorlton, and Carriere (1995) for plutonic, metamorphic, and sedimentary exposures are $14.2,9.1$, and 8.4 per $10^{3}$ linear kilometers, respectively. In other words, the distribution of bodies of each rock type are such that one would anticipate crossing about a dozen mapped lithologic boundaries for each thousand kilometers of land surface traversed. While differences between these numbers indeed reflect the fact that exposures of plutons are somewhat smaller than those of metamorphic or sedimentary complexes, their absolute magnitudes more closely relate to the continental scale of lithologic variation represented by these maps. While more detailed mapping of smaller areas would almost surely yield higher values of $\lambda$, the basic pattern of size exceedence apparent in Figure 2 would remain.

Although coincidence of topographic, geologic, and cultural size frequencies suggests a fundamental relation between numbers and sizes of political and natural boundaries, it would be naive to argue that either natural or cultural processes are spatially or otherwise completely independent. While smaller basins predominate nearer coasts, most major drainages systems preferentially occupy continental interiors and stable cratons (Potter, 1978); the Orinoco, Amazon, and Parana basins being classic drainages in this regard (Fig. 4). Length of time since nationalization might also have a profound effect on country sizes. Of the six largest U.N. nations (Russia, Canada, United States, China, Brazil, and Australia), four represent relatively recent western nationalization; these also are countries that lie across largely stable cratonic areas of relatively low relief.

As recently noted by Nee (2002), similarity of area frequencies among rivers, outcrops, and nations, alone is no assurance that comparable mechanisms in fact govern resultant distributions (the negative binomial describes numbers of humanhosted parasitic worms as well as distributions of words in Shakespeare). In a somewhat similar vein, it might be argued that the facility of rather straightforward random models to describe sizes of basins, outcrops, and nations might merely reflect the fact that these features vary at a scale over which causative mechanisms cannot be differentiated. For example, the number of countries has increased dramatically over the past five decades (74 in 1946 to 192 in 1995; Alesina and Spolaore, 1997). In spite of the complexity of interrelations that must exist between cultural and economic factors that influence the placement of political boundaries, the statistical predictability of nation areas from net country number and net land area suggests that partitioning of political entities may proceed by more or less random division. This is in part because those processes that lead to political separation or unification are themselves largely indeterminate, but mostly because 
old and new boundaries that define nation size are not infrequently coincident with topographic barriers which reflect the complex interplay between tectonic and hydrologic processes.

\section{REFERENCES}

Alesina, A., and Spolaore, E., 1997, On the number and size of nations: Q. J. Econ., v. 112, no. 4, p. $1027-1056$.

Central Intelligence Agency, 2000, The World Factbook, Retrieved from http://www.cia.gov/ cia/publications/factbook/.

Childe, V. G., 1952, What happened in history: Penguin Books, Harmondsworth, 288 p.

Hack, J. T., 1957, Studies of longitudinal stream profiles in Virginia and Maryland: U.S. Geol. Survey Prof. Paper 294 B, p. 45-97.

Hovius, N., 1998, Controls on sediment supply by large rivers: SEPM Special Publication 59, p. 3-16.

Horton, R. E., 1945, Erosional development of streams and their drainage basins, hydrophysical approach to quantitative morphology: Geol. Soc. Am. Bull., v. 56, no. 3, p. 275-370.

Jenson, S. K., and Dominingue, J. O., 1988, Extracting topographic structure from digital elevation data for geographic information system analysis: Photogrammetric Engineering and Remote Sensing, v. 54, no. 11, p. 1593-1600.

Kirkham, R. V., Chorlton, L. B., and Carriere, J. J., 1995, Generalized geology of the world, in Generalized Geological Map of the World and Linked Databases: Geol. Surv. Canada Open File 2915d (CD-ROM).

Meybeck, M., 1995, Global distribution of lakes, in Lerman, A., Imboden, D. M., and Gat, J. R., eds., Physics and chemistry of lakes, 2nd edn.: Springer-Verlag, Berlin, p. 1-35.

Nee, S., 2002, Thinking big in ecology: Nature, v. 417, p. 229-230, doi: 10.1038/417229a.

Potter, P., 1978, Significance and origin of big rivers: J. Geol., v. 86, no. 1, p. 13-33.

Simon, H. A., 1978, The sizes of things, in Tanur, J. M., ed., Statistics: A guide to the unknown: Holden-Day, San Francisco, p. 240-247.

Schanda, E., 1986, Physical fundamentals of remote sensing: Springer-Verlag, New York, 187 p.

Starr, C. G., 1991, A history of the ancient world, 4th edn.: Oxford University Press, New York, 742 p. 